\title{
Asthma control in pregnancy is associated with pre-conception dietary patterns
}

\author{
Jessica A Grieger ${ }^{1}$, Luke E Grzeskowiak', Lisa G Wood ${ }^{2}$ and Vicki L Clifton ${ }^{1, *}$ \\ ${ }^{1}$ Robinson Research Institute, School of Paediatrics and Reproductive Health, University of Adelaide and Lyell \\ McEwin Hospital, Haydown Road, Elizabeth Vale, SA 51 12, Australia: ${ }^{2}$ Hunter Medical Research Institute, School of \\ Biomedical Science and Pharmacy, University of Newcastle, Kookaburra Circuit, New South Wales, Australia
}

Submitted 1 January 2015: Final revision received 11 February 2015: Accepted 12 March 2015: First published online 24 April 2015

\begin{abstract}
Objective: To examine pre-conception dietary patterns in pregnant asthmatic women and to identify associations between maternal diet and asthma control during pregnancy.

Design: Cross-sectional study. Pre-conception food frequency data were collected retrospectively. Asthma control was assessed using the Global Initiative for Asthma guidelines. Dietary patterns were derived using factor analysis. Binary logistic regression analyses were used to test the association between uncontrolled asthma and each dietary pattern ( $Z$-score), with values presented as odds ratio and $95 \%$ confidence interval.

Setting: Antenatal clinic in a tertiary hospital, Adelaide, Australia, May 2009July 2013.

Subjects: One hundred and fifty-eight asthmatic pregnant women.

Results: Three dietary patterns were identified: (i) 'high protein/fruit' (strong food group loadings for fish, meat, chicken, fruit); (ii) 'high fat/sugar/takeaway' (takeaway foods, crisps, refined grains); and (iii) 'vegetarian-type' (vegetables, fruit, soya milk, whole grains). A 1 sD increase in score on the high fat/sugar/ takeaway pattern was associated with increased likelihood of uncontrolled asthma (adjusted $\mathrm{OR}=1.54 ; 95 \% \mathrm{CI} 1.07,2 \cdot 23 ; P=0.022$ ). Women with uncontrolled asthma ( $n$ 115) had higher energy-adjusted intakes of saturated fat, monounsaturated fat, carbohydrate, sugar and fibre compared with women with controlled asthma ( $n$ 43, all $P \leq 0 \cdot 05$ ).

Conclusions: Pre-pregnancy dietary patterns may influence maternal asthma control. Our work highlights the importance of achieving a healthy diet before pregnancy that is low in saturated fat, sugar and takeaway foods, and therefore higher in lean meats, poultry and fish, as well as fruits, vegetables and whole grains. A healthy dietary pattern should be encouraged in all asthmatic women who are of childbearing age, and should additionally be promoted before pregnancy and beyond.
\end{abstract}

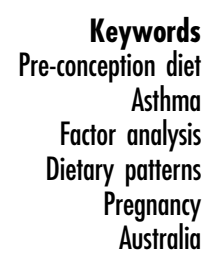

Asthma is a heterogeneous and complex disease, involving alterations in airway structure and airway inflammation. Worldwide, asthma represents one of the most common chronic diseases to affect pregnancies, affecting between 8 and $13 \%$ of the population ${ }^{(1-3)}$. A meta-analysis from 2011 demonstrated that asthma in pregnancy was associated with up to $54 \%$ increased risk for low birth weight, small for gestational age, preterm delivery and pre-eclampsia ${ }^{(4)}$. A subsequent meta-analysis revealed that asthma exacerbations in pregnancy increased the risk for low birth weight (relative risk $(\mathrm{RR})=3.02 ; 95 \% \mathrm{CI} 1.87,4.89$ ) and compared with women with mild asthma, women with moderate to severe asthma were at increased risk for babies born with low birth weight $(\mathrm{RR}=1 \cdot 15 ; 95 \% \mathrm{CI} 1 \cdot 05$, $1 \cdot 26)$ or small for gestational age ( $R R=1 \cdot 24 ; 95 \%$ CI $1 \cdot 15$, $1 \cdot 35)^{(5)}$. These studies suggest that worsening asthma during pregnancy may contribute to poor outcomes for the fetus and that approaches to improve asthma control may be of benefit ${ }^{(6)}$.

In non-pregnant asthmatics, unhealthy diets have been shown to be an underlying contributor to poorly controlled asthma and subsequent risk of asthma exacerbations. In healthy individuals, a single high-fat meal has been linked to increased exhaled nitric oxide ${ }^{(7)}$ and in non-obese asthmatics, a high-fat meal increased neutrophilic inflammation and attenuation of airway 
bronchodilator response ${ }^{(8)}$. A low-fibre, high-fat diet has been linked to worse airway inflammation and lung function in severe asthmatics ${ }^{(9)}$. Furthermore, a diet low in fruits and vegetables has been shown to increase the risk of asthma exacerbation by twofold ${ }^{(10)}$. In pregnancy, altered food patterns have previously been associated with excess gestational weight gain ${ }^{(11)}$, risk for small for gestational age ${ }^{(12)}$, risk of preterm delivery ${ }^{(13)}$ and development of childhood allergies ${ }^{(14)}$. However, the connection between dietary intake and asthma control in pregnancy is not clear.

Only one study to date has assessed dietary intakes in pregnant women with asthma in which nutrient intake was generally higher in mildly asthmatic women, yet lower in moderate to severe asthmatics, compared with pregnant women without asthma ${ }^{(15)}$. Moreover, little attention has been paid to maternal dietary intakes pre-conception and the potential impact this might have on maternal asthma control. If pre-conception diet is linked to asthma control, this would present an ideal time and opportunity to consume a healthy diet to control asthma during pregnancy, thus optimising subsequent perinatal outcomes.

The aims of the present study were to: (i) identify associations between pre-conception dietary patterns and maternal asthma control; and (ii) determine whether there are any differences in dietary intakes between women with controlled $v$. uncontrolled asthma. We hypothesise that pre-conception diet quality influences maternal asthma control during pregnancy.

\section{Methods}

\section{Study setting and population}

The current retrospective, cross-sectional study was part of a larger prospective cohort study from the Lyell McEwin Hospital, Adelaide, Australia, assessing the effects of asthma during pregnancy on the mother, placenta and baby. Pregnant women aged $>18$ years and attending their first antenatal visit were invited to participate. Recruitment and data collection for all women and their babies took place between May 2009 and July 2013. Of the 400 pregnant women who consented, ninety-one women withdrew from further participation due to the following: unable to be contacted ( $n$ 10), could not attend appointments/not interested ( $n$ 56), relocated ( $n$ 9), miscarriage ( $n$ 12) or voluntary termination of pregnancy $(n 4)$, leaving 309 women to be analysed. The project was approved by The Queen Elizabeth Hospital and Lyell McEwin Hospital Human Research Ethics Committee and The University of Adelaide Human Research Ethics Committee. All women gave written informed consent. We have recently examined the relationship between pre-conception dietary patterns in a sample of 309 pregnant women ${ }^{(13)}$. We now present data from a subgroup of asthmatic women ( $n$ 159), in whom we have used the same dietary pattern analysis.

\section{Maternal data collection}

At the first antenatal clinic visit, maternal body weight was measured to the nearest $0 \cdot 1 \mathrm{~kg}$ using calibrated electronic scales (Professional Medical Scale, ScalesPlus, Australia) and height was measured by a wall-mounted stadiometer. BMI was calculated as [weight $(\mathrm{kg})] /[\text { height }(\mathrm{m})]^{2}$. Previous obstetric history, medical, mental and surgical health information, and socio-economic status (Socio-Economic Indexes for Areas) were obtained from medical records. Gestational age was determined by date of the last menstrual period and confirmed at 18-week ultrasound. Smoking history was recorded: women who did not smoke at any stage during pregnancy or who were former smokers (i.e. quit a median of 3 years ago) were classified as non-smokers, while current smokers and those who quit smoking in pregnancy (median 5.5 weeks' gestation) were classified as smokers.

\section{Asthma assessment}

Women attending their first booking visit at the Lyell McEwin Hospital antenatal clinic were identified as controls (non-asthmatic) or asthmatics, by the attending midwife. To determine asthma, the midwife asked 'Have you been told by a doctor that you have asthma?' and 'Have you used any asthma medications in the last year like salbutamol or a preventer?' Women identified as having asthma received a baseline assessment of their asthma during their first study visit (median 13 weeks' gestation). Given the importance of evaluating asthma control, rather than asthma severity, to guide asthma management decisions ${ }^{(16)}$, asthma control was assessed using the Global Initiative for Asthma (GINA) guidelines ${ }^{(17)}$. These guidelines define asthma control as: minimal or no daytime symptoms; no limitations of daily activities; no nocturnal symptoms; minimal or no need for rescue therapy and normal lung function ${ }^{(17)}$. Therefore, based on current symptoms women were identified as having either uncontrolled or partly controlled/controlled asthma. Lung function was assessed using an EasyOne diagnostic spirometer (Niche Medical, Zurich, Switzerland). Forced expiratory volume at one second $\left(\mathrm{FEV}_{1}\right)$ and forced vital capacity (FVC) were measured before and after administration of salbutamol. Predicted values for lung function were calculated based on women's height and age according to the equations of Gore et $a l^{(18)}$.

\section{Dietary intakes and food group consumption}

At the first antenatal visit (median 13 weeks' gestation), the validated Cancer Council of Victoria's Dietary Questionnaire for Epidemiological Studies FFQ was used to obtain dietary intake data covering the 12 months prior to pregnancy. One hundred different foods $(\mathrm{g} / \mathrm{d})$ were obtained from the FFQ and were assigned into thirty-three food groups $(\mathrm{g} / \mathrm{d})$, based on a previous Australian study $^{(19)}$ and used for analysis. 


\section{Factor analysis}

Dietary patterns were derived using factor analysis with factor loadings extracted using the principal component method and varimax/orthogonal rotation. The number of dietary patterns identified was based on eigenvalues $>1.5$, on identification of a break point in the scree plot and on interpretability ${ }^{(20)}$. Using these criteria, a three-factor solution was chosen and re-run with the resulting factor scores saved and converted to $Z$-scores for analysis. Items with factor loadings $>0.25$ were considered as the items of relevance for the identified factor. These items represent the foods most highly related to the identified factor ${ }^{(21)}$. Foods that cross-loaded on several factors were retained. Inter-item reliability for each factor was assessed using Cronbach's $\alpha$ coefficients. Three hundred and nine women had complete FFQ data and the three major dietary patterns that were identified in the factor analysis have been published ${ }^{(13)}$.

\section{Energy adjustment}

Due to the potential for confounding due to differences in total energy intake, we analysed the relationship between both absolute and energy-adjusted nutrient intakes and the presence of uncontrolled asthma. Energy adjustment of nutrient intake was performed using the residuals method, in accordance with previously published descriptions ${ }^{(22)}$. The residuals method involves performing a linear regression analysis with nutrient intake as the dependent variable and total energy intake as the independent variable for each nutrient. This regression equation calculates the expected mean nutrient intake of the study population according to the mean total energy intake of the study population. Subsequently, the energyadjusted intake for each individual was calculated by adding the expected mean macronutrient intake of the study population to the residual derived from the regression analysis.

\section{Statistical analysis}

Frequencies and descriptive statistics are expressed as number and percentage and as mean and standard deviation, respectively. Prior to hypothesis testing, data were examined for normality. Distribution was normal except for $\alpha$-carotene, $\beta$-carotene, lutein, lycopene and long-chain $n$-3 PUFA, which were normalised using natural logarithmic transformation. Calculation of BMI categories was carried out in accordance with the WHO criteria $^{(23)}$. Pearson correlation coefficients were used to test the associations between dietary pattern scores and nutrient intakes. Binary logistic regression analyses were used to test the association between uncontrolled asthma and each dietary pattern ( $Z$-score), with values presented as odds ratio and $95 \%$ confidence interval. All analyses were undertaken adjusting for potential confounders, including maternal age, maternal BMI, smoking status (never/former, quit in pregnancy/current), socio-economic status (level 1 or $\geq 2$ ), parity $(0$ or $\geq 1$ ) and ethnicity (Caucasian or other). Multicollinearity was tested using the variance inflation factor, in which no multicollinearity was observed between any of the independent variables. Differences in mean nutrient intakes between women with controlled and uncontrolled asthma were compared using an unpaired $t$ test. Binary logistic regression analyses were used to test the association between uncontrolled asthma and each nutrient, while adjusting for potential confounders including maternal age, smoking status, socioeconomic status, BMI and parity. Statistical significance was considered at $P<0 \cdot 05$. All statistical procedures were carried out using the statistical software package IBM SPSS Statistics version 19.

\section{Results}

Characteristics of the 158 asthmatic women in the current sample are reported in Table 1 . There was no difference in mean weight gain during pregnancy between those with

Table 1 Characteristics of the study population at the first visit*: asthmatic pregnant women ( $n$ 158), Adelaide, Australia, May 2009July 2013

\begin{tabular}{|c|c|c|}
\hline & Mean or $n$ & SD or $\%$ \\
\hline Maternal age (years) $\dagger$ & 27 & 6 \\
\hline \multicolumn{3}{|l|}{ Gravidity $\ddagger$} \\
\hline$\geq 2$ & 106 & 65 \\
\hline \multicolumn{3}{|l|}{ Parity } \\
\hline$\geq 1$ & 57 & 35 \\
\hline $\mathrm{BM} \overline{\mathrm{M}}\left(\mathrm{kg} / \mathrm{m}^{2}\right) \dagger$ & 28.34 & $7 \cdot 11$ \\
\hline \multicolumn{3}{|l|}{ Smoking statusł } \\
\hline Never/former & 112 & 69 \\
\hline Quit in pregnancy & 18 & 11 \\
\hline Current smoker & 33 & 20 \\
\hline \multicolumn{3}{|l|}{ Ethnicitył } \\
\hline Caucasian & 149 & 91 \\
\hline Other & 14 & 9 \\
\hline \multicolumn{3}{|l|}{ Socio-economic status $\ddagger$} \\
\hline 5 (highest) & 9 & 6 \\
\hline 4 & 10 & 6 \\
\hline 3 & 3 & 2 \\
\hline 2 & 51 & 33 \\
\hline 1 (lowest) & 81 & 53 \\
\hline \multicolumn{3}{|l|}{ Asthma medication $\ddagger$} \\
\hline SABA & 112 & 69 \\
\hline SABA + ICS & 11 & 7 \\
\hline SABA + ICS/LABA & 40 & 24 \\
\hline Baseline ICS dose $(\mu \mathrm{g} / \mathrm{d}) \dagger$ & 544 & 362 \\
\hline \multicolumn{3}{|l|}{ Spirometry† } \\
\hline $\mathrm{FEV}_{1}$ (litres) & 2.93 & 0.48 \\
\hline$\%$ predicted $\mathrm{FEV}_{1}$ & 0.92 & 0.11 \\
\hline FVC (litres) & $3 \cdot 66$ & 0.62 \\
\hline$\%$ predicted FVC & 0.98 & 0.12 \\
\hline $\mathrm{FEV}_{1} / \mathrm{FVC}$ & 0.80 & 0.07 \\
\hline $\mathrm{FEV}_{1} / \mathrm{FVC} \%$ & 0.95 & 0.07 \\
\hline
\end{tabular}

SABA, slow-acting $\beta$ agonist; ICS, inhaled corticosteroid; LABA, long-acting $\beta$ agonist; $F E V_{1}$, forced expiratory volume at one second, $F V C$, forced vital capacity.

*Median 13 weeks' gestation.

†Values presented are mean and standard deviation.

$\ddagger$ Values presented are number and percentage. 
Table 2 Pearson correlation coefficients $(r)$ between dietary pattern scores and nutrient intakes among asthmatic pregnant women ( $n$ 158), Adelaide, Australia, May 2009-July 2013

\begin{tabular}{|c|c|c|c|}
\hline Nutrient & High protein/fruit & High fat/sugar/takeaway & Vegetarian-type \\
\hline Energy $(\mathrm{kJ})$ & 0.58 & 0.69 & \\
\hline Total fat (g) & 0.58 & 0.71 & \\
\hline Saturated fat $(g)$ & 0.52 & 0.72 & \\
\hline Polyunsaturated fat (g) & 0.48 & 0.52 & \\
\hline Monounsaturated fat $(\mathrm{g})$ & 0.62 & 0.69 & \\
\hline Protein $(\mathrm{g})$ & 0.77 & 0.52 & \\
\hline Carbohydrate (g) & & 0.66 & \\
\hline Sugar (g) & 0.43 & 0.42 & \\
\hline Fibre $(\mathrm{g})$ & 0.44 & & 0.61 \\
\hline $\mathrm{Ca}(\mathrm{mg})$ & 0.51 & & \\
\hline Cholesterol (mg) & 0.74 & 0.51 & \\
\hline Dietary folate equivalents $(\mu \mathrm{g})$ & 0.50 & & 0.57 \\
\hline $\mathrm{Fe}(\mathrm{mg})$ & 0.65 & 0.50 & \\
\hline $\mathrm{Mg}(\mathrm{mg})$ & 0.65 & 0.43 & 0.41 \\
\hline Niacin equivalents (mg) & 0.75 & 0.51 & \\
\hline Riboflavin (mg) & 0.51 & 0.42 & 0.41 \\
\hline $\mathrm{Na}(\mathrm{mg})$ & 0.68 & 0.62 & \\
\hline Thiamin (mg) & 0.49 & 0.47 & \\
\hline $\mathrm{Zn}(\mathrm{mg})$ & 0.70 & 0.55 & \\
\hline Vitamin C (mg) & 0.40 & & 0.49 \\
\hline Vitamin E (mg) & 0.42 & 0.58 & 0.47 \\
\hline Vitamin A retinol equivalents $(\mu \mathrm{g})$ & & 0.51 & 0.56 \\
\hline Linoleic acid (mg) & & 0.53 & \\
\hline a-Linolenic acid (mg) & & 0.75 & \\
\hline Long-chain n-3 PUFA (mg) & 0.88 & & \\
\hline
\end{tabular}

Only correlations of $r>0.40$ are included. All correlations are significant $(P \leq 0.01)$.

Table 3 Odds ratios for likelihood of uncontrolled asthma* at the first visit during pregnancy according to pre-conception dietary pattern among asthmatic pregnant women (n 158), Adelaide, Australia, May 2009-July 2013

\begin{tabular}{|c|c|c|c|c|c|c|}
\hline & Unadjusted OR & $95 \% \mathrm{Cl}$ & $P$ & Adjusted OR $†, \ddagger$ & $95 \% \mathrm{Cl}$ & $P$ \\
\hline \multicolumn{7}{|c|}{ Uncontrolled asthma at first visit $(A C Q>1.5)$} \\
\hline High protein/fruit & 1.09 & $0.85,1.41$ & 0.485 & 1.04 & $0.80,1.37$ & 0.757 \\
\hline High fat/sugar/takeaway & 1.59 & $1 \cdot 13,2 \cdot 25$ & 0.008 & 1.54 & $1 \cdot 07,2 \cdot 23$ & 0.022 \\
\hline Vegetarian type & $1 \cdot 10$ & $0.78,1.56$ & 0.579 & 1.26 & $0.86,1.84$ & 0.231 \\
\hline
\end{tabular}

$\mathrm{ACQ}$, Asthma Control Questionnaire.

*According to Global Initiative for Asthma (GINA) classification measured in the first trimester ${ }^{(17)}$ at median 13 weeks' gestation.

†Adjusted for maternal age, maternal BMI, smoking status (never/former, quit in pregnancy/current), socio-economic status (level 1 or $\geq 2$ ), parity ( 0 or $\geq 1$ ) and ethnicity (Caucasian or other).

‡lndicates change in risk per $1 \mathrm{SD}$ increase in factor score.

controlled $v$. uncontrolled asthma $(11 \cdot 13(\operatorname{se} 0.55) \mathrm{kg} v$. 9.03 (se 1.01) kg, $P=0.084$ ).

Three dietary patterns were identified (see online supplementary material, Supplemental Table 1). Factor 1 was labelled 'high protein/fruit' as there were several protein-rich food groups loading on the pattern (i.e. fish, meat, chicken) as well as fresh fruit and canned fruit. Factor 2 was labelled 'high fat/sugar/takeaway' as takeaway foods, crisps, fried potato, refined grains and cakes/ pastries loaded on this pattern. Factor 3 was labelled 'vegetarian-type' as many of the food groups loading on this pattern were different types of vegetables, soya milk and whole grains. There were strong correlations between the high protein/fruit pattern and long-chain $n$-3 PUFA, protein, cholesterol and $\mathrm{Zn}$; there were strong correlations between the high fat/sugar/takeaway pattern and total fat, $\alpha$-linolenic acid, SFA and $\mathrm{Na}$; and there were strong to moderate correlations between the vegetarian-type pattern and fibre, dietary folate and vitamin A retinol equivalents (Table 2 ).

Asthma control was measured at a median of 13 weeks' gestation. In multivariate regression analysis, a $1 \mathrm{SD}$ increase in the score on the high fat/sugar/takeaway pattern was associated with $50 \%$ increased likelihood for uncontrolled asthma (adjusted OR $=1.54 ; 95 \%$ CI 1.07, 2.23; $P=0.022$; Table 3). After adjusting for total energy intake, women with uncontrolled asthma had higher intakes of SFA, MUFA, total carbohydrate, sugar and fibre (Table 4). For each additional $40 \mathrm{~g}$ of carbohydrate intake, the odds of uncontrolled asthma increased by $40 \%$, while for each additional $10 \mathrm{~g}$ increase in sugar, the odds of uncontrolled asthma increased by $10 \%$ (Table 4). 
Table 4 Mean dietary intakes and nutrient density of the diet according to controlled and uncontrolled asthma status among asthmatic pregnant women ( $n$ 158), Adelaide, Australia, May 2009-July 2013

\begin{tabular}{|c|c|c|c|c|c|c|c|c|}
\hline & \multicolumn{2}{|c|}{ Controlled asthma ( $n$ 115) } & \multicolumn{2}{|c|}{ Uncontrolled asthma ( $n$ 43) } & \multirow[b]{2}{*}{$P$ value* } & \multirow[b]{2}{*}{ Adjusted OR†,‡ } & \multirow[b]{2}{*}{$95 \% \mathrm{Cl}$} & \multirow[b]{2}{*}{$P$ value } \\
\hline & Mean & SE & Mean & SE & & & & \\
\hline \multicolumn{9}{|l|}{ Absolute intake } \\
\hline Energy (kJ/d) & 7700 & 331 & 9352 & 619 & 0.026 & 1.00 & $1.00,1.00$ & 0.201 \\
\hline Protein $(\mathrm{g} / \mathrm{d})$ & 90.6 & 5.15 & 105 & 8.29 & 0.216 & 1.01 & $0.99,1.01$ & 0.111 \\
\hline Total fat $(\mathrm{g} / \mathrm{d})$ & $80 \cdot 9$ & 3.95 & $99 \cdot 2$ & 7.57 & 0.040 & 1.01 & $0.99,1.02$ & 0.071 \\
\hline SFA $(g / d)$ & $35 \cdot 0$ & 1.80 & $43 . \overline{7}$ & 3.45 & 0.031 & 1.02 & $0.99,1.04$ & 0.086 \\
\hline PUFA (g/d) & $10 \cdot 6$ & 0.46 & $12 \cdot 1$ & 0.96 & 0.143 & 1.05 & $0.97,1.13$ & 0.206 \\
\hline MUFA (g/d) & $28 \cdot 4$ & 1.48 & $35 \cdot 1$ & $2 \cdot 84$ & 0.045 & 1.03 & $1.00,1.05$ & 0.048 \\
\hline Carbohydrate (g/d) & 190 & 7.07 & 234 & 14.4 & 0.006 & 1.01 & $1.00,1.01$ & 0.020 \\
\hline Sugar $(g / d)$ & 85.4 & 3.65 & 103 & $6 \cdot 11$ & 0.028 & 1.01 & $1.00,1.02$ & 0.015 \\
\hline Fibre $(g / d)$ & $18 \cdot 2$ & 0.70 & $23 \cdot 0$ & $1 \cdot 28$ & 0.003 & 1.08 & $1.03,1.14$ & 0.002 \\
\hline Cholesterol (mg/d) & 294 & $17 \cdot 3$ & 327 & 28.4 & 0.379 & 1.00 & $0.99,1.00$ & 0.330 \\
\hline \multicolumn{9}{|l|}{ Energy-adjusted intake } \\
\hline Protein $(\mathrm{g} / \mathrm{d})$ & 88.3 & 5.06 & 102 & 8.12 & 0.225 & 1.01 & $0.99,1.01$ & 0.113 \\
\hline Total fat $(\mathrm{g} / \mathrm{d})$ & $69 \cdot 1$ & $2 \cdot 72$ & $80 \cdot 7$ & $6 \cdot 80$ & 0.092 & 1.01 & $0.99,1.02$ & 0.572 \\
\hline SFA $(g / d)$ & 33.8 & 1.75 & $42 \cdot 3$ & 3.37 & 0.031 & 1.02 & $0.99,1.04$ & 0.088 \\
\hline PUFA $(\mathrm{g} / \mathrm{d})$ & 8.87 & 0.39 & $10 \cdot 0$ & 0.85 & 0.202 & 1.05 & $0.96,1.14$ & 0.283 \\
\hline MUFA (g/d) & $25 \cdot 9$ & 1.37 & $32 \cdot 1$ & 2.64 & 0.047 & 1.03 & $1.00,1.06$ & 0.049 \\
\hline Carbohydrate (g/d) & 193 & $7 \cdot 22$ & 239 & 14.6 & 0.006 & 1.01 & $1.00,1.02$ & 0.014 \\
\hline Sugar $(g / d)$ & 87.9 & 3.73 & 106 & $6 \cdot 27$ & 0.027 & 1.01 & $1.00,1.01$ & 0.020 \\
\hline Fibre $(g / d)$ & $20 \cdot 0$ & 0.77 & $25 \cdot 1$ & 1.37 & 0.003 & 1.07 & $1.03,1.13$ & 0.003 \\
\hline Cholesterol (mg/d) & 296 & $17 \cdot 4$ & 330 & 28.6 & 0.374 & 1.00 & $0.99,1.00$ & 0.325 \\
\hline
\end{tabular}

${ }^{*} P$ value represents differences between controlled asthma and uncontrolled asthma groups.

†Logistic regression analysis for each dietary nutrient that included the following covariates in the model: maternal age, smoking status, socio-economic status, BMI and parity.

łIndicates change in risk per unit of dietary intake.

\section{Discussion}

The current study represents the first piece of evidence linking pre-conception dietary patterns in pregnant women to asthma control. We identified that a dietary pattern containing higher consumption of takeaway foods, fried potato, crisps and refined grains was associated with uncontrolled asthma. Women with uncontrolled asthma had higher intakes of SFA, MUFA, total carbohydrate, sugar and fibre, such that for each additional $40 \mathrm{~g}$ of carbohydrate intake, equivalent to 2.5 slices of white bread per day, the odds of uncontrolled asthma increased by $40 \%$, while for each additional $10 \mathrm{~g}$ increase in sugar intake, equivalent to two teaspoons of added sugar per day, the odds of uncontrolled asthma increased by $10 \%$.

Our findings are important as human epidemiological studies have shown in asthmatic adults that higher fat and lower fibre intakes were associated with worse airway inflammation and lung function ${ }^{(9)}$ and fast-food consumption $\geq 3$ times per week was associated with increased risk of severe asthma in children and adolescents $^{(24)}$. Most recently, in a meta-analysis of observational studies, total intake of fruit and vegetables was inversely associated with risk of asthma in adults (six studies: $\mathrm{RR}=0.64 ; 95 \%$ CI 0.41, 1.01) and children (two studies: $\mathrm{RR}=0.57 ; 95 \% \mathrm{CI} 0.42,0.77$ ), but higher consumption of fruit and vegetables during pregnancy was not associated with risk of asthma in offspring ${ }^{(25)}$. Acute studies in human subjects have demonstrated that a single high-fat meal increased exhaled nitric oxide ${ }^{(7)}$, increased circulating fatty acid levels and percentage neutrophils in sputum, and attenuated airway bronchodilator responses ${ }^{(8)}$. Comparatively, a randomised controlled trial showed that two servings of fruit and five servings of vegetables daily reduced the risk of asthma exacerbation in adults with stable asthma ${ }^{(10)}$. Animal studies have also shown that a high-fat diet can induce pro-inflammatory responses both systemically $^{(26)}$ and in the lungs ${ }^{(27)}$. SFA can induce an inflammatory response via activation of pattern recognition receptors $^{(28)}$ and by activation of downstream proinflammatory signalling pathways ${ }^{(29)}$. Worsening asthma in pregnancy could therefore be attributable in part to dietary intake.

Previous studies have shown that pre-conception diet does not differ significantly from dietary habits during pregnancy ${ }^{(30,31)}$. Although the mechanisms linking preconception diet with maternal and neonatal outcomes have not been investigated in human subjects, the Dutch famine studies that occurred during 1944-1945(32,33) are probably the closest data that show how the timing of nutrients from the mother to the fetus impacts perinatal outcomes in both the short and long term. It was identified that babies exposed to famine in late gestation had reduced growth compared with babies not exposed to famine, whereas babies who were exposed to famine in early gestation were heavier at birth ${ }^{(34)}$. Interestingly, in adulthood, those who were exposed to famine in early gestation (and were heavier at birth) had a more atherogenic lipid profile ${ }^{(35)}$, a higher BMI ${ }^{(35,36)}$ and typically had 
higher risk of $\mathrm{CHD}^{(37,38)}$. The prevalence of obstructive airways disease was increased in people exposed to famine in mid-gestation ( $\mathrm{OR}=1 \cdot 7 ; 95 \% \mathrm{CI} 1 \cdot 1,2 \cdot 6)$ and non-significantly higher in those exposed in early gestation $(\mathrm{OR}=1.5 ; 95 \% \mathrm{CI} 0.9,2 \cdot 6)^{(39)}$. Thus, alterations in fetal nutritional supply can drive developmental adaptations influencing growth and metabolism. These results, and ours, demonstrate how nutritional challenges periconceptionally and in early gestation can influence maternal and perinatal outcomes.

A limitation of the present study includes the relative small sample size of asthmatic women, which is reflected in the relatively large confidence intervals generated in the multivariate analysis. As such, it is not possible to rule out a smaller, yet still clinically significant difference between the dietary patterns and asthma control, beyond those observed in the study. Therefore, the full effect of maternal diet on asthma control is still worthy of investigation in subsequent larger studies. The FFQ is a reliable tool covering long-term food intake and the FFQ used in the current study has been validated in women of childbearing age ${ }^{(40)}$, as well as in young ${ }^{(41)}$ and older ${ }^{(42)}$ adults. However, use of the questionnaire also has limitations including memory recall, and several details of dietary intake are not measured; thus quantification of intake is not as accurate as with repeated $24 \mathrm{~h}$ recalls or food records. Inaccuracies may also result from an incomplete listing of all possible foods and from errors in frequency and usual serving size estimations. In addition, although women were informed of the dietary intake period to cover, it is possible that current (i.e. first trimester) dietary intakes might have influenced the records. However, as this was a retrospective report about dietary intakes prior to pregnancy, a food frequency approach was necessary. Unpublished data from our $24 \mathrm{~h}$ recalls, which were collected throughout gestation, indicated that similar foods (i.e. fruits, takeaways, butter, cereal-based dishes, vegetables) were consumed by a high percentage of women. In the literature, there is limited information on diet before pregnancy; however, the few studies that have been published reported minimal differences in dietary patterns just prior to and during pregnancy ${ }^{(30,31)}$, in which one of these studies identified the dietary patterns persisted 6 months postpartum ${ }^{(31)}$. Strengths of the present study include the detailed assessment of asthma control and the use of lung function tests to confirm asthma status. Further studies have the potential to expand on these findings by assessing dietary patterns and the relationship to asthma exacerbations, and conducting randomised controlled trials in asthmatic pregnant women to assess the positive effects of dietary manipulation on asthma outcomes.

Dietary intake is an important modifiable risk factor for asthma and our data suggest that nutrition pre-pregnancy influences maternal asthma control during pregnancy. This work highlights the importance of promoting a healthy diet that is low in saturated fat, sugar and takeaway foods, and therefore higher in lean meats, poultry and fish, as well as fruits, vegetables and whole grains. This dietary pattern needs to be encouraged to all asthmatic women who are of childbearing age, and should additionally be promoted during pregnancy and beyond.

\section{Acknowledgements}

Acknowledgements: The authors acknowledge Karen Rivers, Sarah Riley, Kate Roberts-Thomson, Jessica Forrest, Annette Osei-Kumah and Nicolette Hodyl for their contribution to the management of the study and collection of the data. Financial support: Funding support was provided by the National Health and Medical Research Council Senior Research Fellowship (ID 510703 to V.L.C.) and the National Health and Medical Research Council Early Career Fellowship (ID 1070421 to L.E.G.). The National Health and Medical Research Council had no role in the design, analysis or writing of this article. Conflict of interest: None. Authorship: J.A.G. was responsible for the conception and design and acquisition of data; L.E.G. was responsible for the analysis and interpretation of data; J.A.G. was responsible for drafting the article; all authors were responsible for revising the article critically for important intellectual content and providing final approval of the version to be published. Ethics of human subject participation: The project was approved by The Queen Elizabeth Hospital and Lyell McEwin Hospital Human Research Ethics Committee and The University of Adelaide Human Research Ethics Committee. All participants gave written informed consent.

\section{Supplementary material}

To view supplementary material for this article, please visit http://dx.doi.org/10.1017/S1368980015001226

\section{References}

1. Clark JM, Hulme E, Devendrakumar V et al. (2007) Effect of maternal asthma on birthweight and neonatal outcome in a British inner-city population. Paediatr Perinat Epidemiol 21, 154-162.

2. Kurinczuk JJ, Parsons DE, Dawes V et al. (1999) The relationship between asthma and smoking during pregnancy. Women Health 29, 31-47.

3. Kwon HL, Belanger K \& Bracken MB (2003) Asthma prevalence among pregnant and childbearing-aged women in the United States: estimates from national health surveys. Ann Epidemiol 13, 317-324.

4. Murphy VE, Namazy JA, Powell H et al. (2011) A metaanalysis of adverse perinatal outcomes in women with asthma. BJOG 118, 1314-123.

5. Namazy JA, Murphy VE, Powell H et al. (2013) Effects of asthma severity, exacerbations and oral corticosteroids on perinatal outcomes. Eur Respir J 41, 1082-1090. 
6. Powell H, Murphy VE, Taylor DR et al. (2011) Management of asthma in pregnancy guided by measurement of fraction of exhaled nitric oxide: a double-blind, randomised controlled trial. Lancet 378, 983-990.

7. Rosenkranz SK, Townsend DK, Steffens SE et al. (2010) Effects of a high-fat meal on pulmonary function in healthy subjects. Eur J Appl Physiol 109, 499-506.

8. Wood LG, Garg ML \& Gibson PG (2011) A high-fat challenge increases airway inflammation and impairs bronchodilator recovery in asthma. J Allergy Clin Immunol 127, 1133-1140.

9. Berthon BS, Macdonald-Wicks LK, Gibson PG et al. (2013) Investigation of the association between dietary intake, disease severity and airway inflammation in asthma. Respirology 18, 447-454.

10. Wood LG, Garg ML, Smart JM et al. (2012) Manipulating antioxidant intake in asthma: a randomized controlled trial. Am J Clin Nutr 96, 534-543.

11. Uusitalo U, Arkkola T, Ovaskainen ML et al. (2009) Unhealthy dietary patterns are associated with weight gain during pregnancy among Finnish women. Public Health Nutr 12, 2392-2399.

12. Thompson JM, Wall C, Becroft DM et al. (2010) Maternal dietary patterns in pregnancy and the association with small-for-gestational-age infants. BrJ Nutr 103, 1665-1673.

13. Grieger JA, Grzeskowiak LE \& Clifton VL (2014) Preconception dietary patterns in human pregnancies are associated with preterm delivery. J Nutr 144, 1075-1080.

14. Miyake Y, Okubo H, Sasaki S et al. (2011) Maternal dietary patterns during pregnancy and risk of wheeze and eczema in Japanese infants aged 16-24 months: the Osaka Maternal and Child Health Study. Pediatr Allergy Immunol 22, 734741.

15. McLernon PC, Wood LG, Murphy VE et al. (2012) Circulating antioxidant profile of pregnant women with asthma. Clin Nutr 31, 99-107.

16. Humbert M, Holgate S, Boulet LP et al. (2007) Asthma control or severity: that is the question. Allergy 62, 95-101.

17. Global Initiative for Asthma (2012) GINA Report. Global Strategy for Asthma Management Prevention. http://www. ginasthma.org/ (accessed March 2013).

18. Gore CJ, Crockett AJ, Pederson DG et al. (1995) Spirometric standards for healthy adult lifetime nonsmokers in Australia. Eur Respir J 8, 773-782.

19. Ambrosini GL, Oddy WH, Robinson M et al. (2009) Adolescent dietary patterns are associated with lifestyle and family psycho-social factors. Public Health Nutr 12, 1807-1815.

20. Schulze MB, Hoffmann K, Kroke A et al. (2003) An approach to construct simplified measures of dietary patterns from exploratory factor analysis. Br J Nutr 89, 409419.

21. Kline PK (1994) An Easy Guide to Factor Analysis. London/ New York: Routledge.

22. Willett WC \& Stampfer M (1998) Implications of total energy intake for epidemiologic analysis. In Nutritional Epidemiology, 2nd ed., pp. 273-301 [WC Willett, editor]. New York: Oxford University Press, Inc.

23. World Health Organization (2013) Obesity and Overweight. Fact Sheet no. 311. Geneva: WHO; available at http://www. who.int/mediacentre/factsheets/fs311/en/

24. Ellwood P, Asher MI, Garcia-Marcos L et al. (2013) Do fast foods cause asthma, rhinoconjunctivitis and eczema?
Global findings from the International Study of Asthma and Allergies in Childhood (ISAAC) phase three. Thorax $\mathbf{6 8}$, 351-360.

25. Seyedrezazadeh E, Moghaddam MP, Ansarin K et al. (2014) Fruit and vegetable intake and risk of wheezing and asthma: a systematic review and meta-analysis. Nutr Rev 72, 411-428.

26. Chalkiadaki A \& Guarente L (2012) High-fat diet triggers inflammation-induced cleavage of SIRT1 in adipose tissue to promote metabolic dysfunction. Cell Metab 16, 180-188.

27. de Vries A, Hazlewood L, Fitch PM et al. (2009) High-fat feeding redirects cytokine responses and decreases allergic airway eosinophilia. Clin Exp Allergy 39, 731-739.

28. Scott HA, Jensen ME \& Wood LG (2014) Dietary interventions in asthma. Curr Pharm Des 20, 1003-1010.

29. Kennedy A, Martinez K, Chuang CC et al. (2009) Saturated fatty acid-mediated inflammation and insulin resistance in adipose tissue: mechanisms of action and implications. J Nutr 139, 1-4.

30. Crozier SR, Robinson SM, Godfrey KM et al. (2009) Women's dietary patterns change little from before to during pregnancy. J Nutr 139, 1956-1963.

31. Cuco G, Fernandez-Ballart J, Sala J et al. (2006) Dietary patterns and associated lifestyles in preconception, pregnancy and postpartum. Eur J Clin Nutr 60, 364-371.

32. Hart N (1993) Famine, maternal nutrition and infant mortality: a re-examination of the Dutch hunger winter. Popul Stud 47, 27-46.

33. Lumey LH \& Stein AD (1997) In utero exposure to famine and subsequent fertility: the Dutch Famine Birth Cohort Study. Am J Public Health 87, 1962-1966.

34. Stein AD, Zybert PA, van de Bor M et al. (2004) Intrauterine famine exposure and body proportions at birth: the Dutch Hunger Winter. Int J Epidemiol 33, 831-836.

35. Roseboom TJ, van der Meulen JH, Osmond C et al. (2000) Plasma lipid profiles in adults after prenatal exposure to the Dutch famine. Am J Clin Nutr 72, 1101-1106.

36. Roseboom TJ, van der Meulen $\mathrm{JH}$, Ravelli AC et al. (2000) Plasma fibrinogen and factor VII concentrations in adults after prenatal exposure to famine. $\mathrm{Br} J$ Haematol 111, 112-117.

37. Ravelli AC, van Der Meulen JH, Osmond C et al. (1999) Obesity at the age of $50 \mathrm{y}$ in men and women exposed to famine prenatally. Am J Clin Nutr 70, 811-816.

38. Roseboom TJ, van der Meulen JH, Osmond C et al. (2000) Coronary heart disease after prenatal exposure to the Dutch famine, 1944-45. Heart 84, 595-598.

39. Lopuhaa CE, Roseboom TJ, Osmond C et al. (2000) Atopy, lung function, and obstructive airways disease after prenatal exposure to famine. Thorax 55, 555-561.

40. Hodge A, Patterson AJ, Brown WJ et al. (2000) The Anti Cancer Council of Victoria FFQ: relative validity of nutrient intakes compared with weighed food records in young to middle-aged women in a study of iron supplementation. Aust N Z J Public Health 24, 576-583.

41. Hebden L, Kostan E, O'Leary F et al. (2013) Validity and reproducibility of a food frequency questionnaire as a measure of recent dietary intake in young adults. PLoS One 8, e75156.

42. Xinying PX, Noakes M \& Keogh J (2004) Can a food frequency questionnaire be used to capture dietary intake data in a 4 week clinical intervention trial? Asia Pac J Clin Nutr 13, 318-323. 